\title{
Clinical Characteristics and Predictors of Mortality in Obese African-Americans with COVID-19: a Single-Center Retrospective Study
}

\author{
Pavani Reddy Garlapati ${ }^{1}$. Suneet Kumar ${ }^{1}$ - Meet Patel ${ }^{1}$. Bidyut Sarker ${ }^{1}$ - Benjamin Tiongson ${ }^{1}$ - Sreedhar Adapa ${ }^{2}$. \\ Sohail Abdul Salim ${ }^{3} \cdot$ Mark K. Adler $^{1} \cdot$ Vijay Reddy Gayam $^{1,4,5,6}$
}

Received: 22 December 2020 / Revised: 21 March 2021 / Accepted: 6 December 2021 / Published online: 13 January 2022

(c) W. Montague Cobb-NMA Health Institute 2021

\begin{abstract}
Background This study aims to add to the body of evidence linking obesity as an established risk factor for COVID-19 infection and also look at predictors of mortality for COVID-19 in the African-Americans (AA) population.

Methods A retrospective cohort study of patients with confirmed COVID-19 infection was done in a community hospital in New York City. The cohort was divided into two groups, with the non-obese group having a BMI $<30 \mathrm{~kg} / \mathrm{m}^{2}$ and the obese group with a BMI $\geq 30 \mathrm{~kg} / \mathrm{m}^{2}$. Clinical predictors of mortality were assessed using multivariate regression analysis. Results Among the 469 (AA) patients included in the study, 56.3\% ( $n=264)$ had a BMI $<30 \mathrm{~kg} / \mathrm{m}^{2}$ and $43.7 \%(n=205)$ had a BMI $\geq 30 \mathrm{~kg} / \mathrm{m}^{2}$. Most common comorbidities were hypertension $(n=304,64.8 \%)$, diabetes $(n=200,42.6 \%)$, and dyslipidemia $(n=74,15.8 \%)$. Cough, fever/chills, and shortness of breath had a higher percentage of occurring in the obese group ( 67.8 vs. $55.7 \%, p=0.008 ; 58.0$ vs. $46.2 \%, p=0.011 ; 72.2$ vs. $59.8 \%, p=0.005$, respectively). In-hospital mortality (41.5 vs. $25.4 \%, p<0.001)$ and mechanical ventilation rates (34.6 vs. $22.7 \%, p=0.004)$ were also greater for the obese group. Advanced age $(p=0.034)$, elevated sodium levels $(p=0.04)$, and elevated levels of AST $(0.012)$ were associated with an increase in likelihood of in-hospital mortality in obese group.

Conclusions Our results show that having a BMI that is $\geq 30 \mathrm{~kg} / \mathrm{m}^{2}$ is a significant risk factor in COVID-19 morbidity and mortality. These results highlight the need for caution when managing obese individuals.
\end{abstract}

Keywords COVID-19 · Obesity · African-American · Predictors of mortality

Vijay Reddy Gayam

vgayam@interfaithmedical.com

Pavani Reddy Garlapati

docpavanireddy@gmail.com

Suneet Kumar

suneet302@yahoo.com

Meet Patel

meetpate1263@gmail.com

Bidyut Sarker

bksarker@interfaithmedical.com

Benjamin Tiongson

Bctiongson@gmail.com

Sreedhar Adapa

sreedharadapa@gmail.com

Sohail Abdul Salim

Sohail3553@gmail.com
Mark K. Adler

Madler@interfaithmedical.com

Department of Medicine, Interfaith Medical Center, New York, NY, USA

2 Department of Internal Medicine, Division of Nephrology, Adventist Medical Center, Reedley, CA, USA

3 Department of Medicine, University of Mississippi, Oxford, MS, USA

4 SUNY Downstate University Hospital, New York, NY, USA

5 American University of Antigua, St Johns, Antigua and Barbuda

6 Eastern Section, American Federation for Medical Research, 1545 Atlantic Ave, Brooklyn, NY 11213, USA 


\section{Introduction}

Since the identification of the novel coronavirus, named severe acute respiratory syndrome coronavirus 2 (SARSCoV-2), in December 2019 in Wuhan, China, there have been over twenty-nine million cases in the USA over five hundred thousand deaths (https://covid.cdc.gov/covid-datatracker/\#cases_casesinlast7days). The disease was declared a pandemic in March 2020 by the WHO [1]. Various risk factors have been defined and studied, linking them to morbidity and mortality in cases of COVID-19. These include advanced age, male gender, diabetes, hypertension, cardiovascular diseases, obesity, and chronic kidney disease [2-9]. A study in the UK showed an increased risk of death with obesity. In the same study, the authors analyzed ethnicity and risk of COVID-19 fatalities and found that the Black population were at higher risk of death as compared to the white population (adjusted hazard ratio [aHR] 1.71; 95\% confidence interval [CI] 1.44-2.02) [10].

Leonidas et al., in their study in Bronx, New York, found that under-represented minorities where the prevalence of obesity is higher appear to be affected disproportionately. They also concluded that severe obesity, increasing age, and male sex were independently associated with higher in-hospital mortality and, in general, worse in-hospital outcomes. These factors were also associated with a higher rate of intubation and increasing oxygen requirement [11].

According to the United States census bureau, the AfroAmerican population constitutes $33.8 \%$ of the total population. Approximately one in four adults in Brooklyn is estimated to be obese and at risk for health risks, including diabetes and cardiac events (https://www.census.gov/quick facts/kingscountybrooklynboroughnewyork, http://nyc.gov/ health/epiquery).

We conducted this study as there is limited availability of data in the Afro-American obese patients with COVID-19. The study was aimed to evaluate the clinical characteristics and predictors of mortality in this cohort.

\section{Study Design}

We conducted a retrospective cohort study among patients hospitalized and managed for the COVID-19 infection at an inner-city teaching hospital located in Downtown Brooklyn, New York. Our hospital serves a predominantly AfricanAmerican population. At least $90 \%$ of all patients seen at our main hospital and clinics are African-Americans. Included in our study were all African-American patients admitted and managed for laboratory-confirmed COVID-19 infection with a definitive outcome (discharged or deceased) at the end of data collection.

\section{Ethical Considerations}

Ethical clearance was obtained from the hospital's IRB committee. Because our study was limited to chart review with no patient interactions, the requirement of informed consent was waived.

\section{Data Collection}

Recruitment was systematic over the entire data collection period from March 1st to May 9th, 2020. Demographic, social, clinical, laboratory, and radiologic data were extracted from electronic medical records and entered on an excel data collection sheet. The data collection sheet had inbuilt checks to flag probably incorrectly entered or inappropriate data prompting immediate corrective actions to limit inaccuracies. To further ensure that data extraction was accurate and complete, $10 \%$ of all cases (approximately 40) were randomly assessed for validity and consistency by an independent evaluator (part of the research team) and found to be accurate.

\section{Laboratory Procedures}

Nasopharyngeal swabs were obtained at the time of admission, and COVID-19 was confirmed by the qualitative SARS-CoV-2 real-time polymerase chain reaction. All laboratory methods were in accordance with prescribed standards by regulations. Laboratory tests included blood gases, lactic acid, complete blood count, coagulation profile including d-dimers, serum biochemical tests (including renal and liver function, creatine kinase, lactate dehydrogenase, and electrolytes), troponin I, interleukin-6 (IL-6), serum ferritin, and procalcitonin among others. Chest radiographs, as well as electrocardiograms, were obtained for all patients at the time of presentation. Inpatient management was mainly supportive with respiratory assistance and management of associated co-morbidities as directed by the treating physicians. Patients were either discharged when clinically stable or if they died during hospitalization. Negative virologic results were not a pre-requisite for discharge.

\section{Statistical Analysis}

Data were expressed as median (interquartile range). Univariate analyses were performed using Student's $t$-test for quantitative values and Chi-square for qualitative values. Multivariate regression analysis was modeled to assess for predictors of mortality for patients admitted for COVID-19. 
Variables with $p<0.05$ at univariate analysis were evaluated using multivariate regression analysis. Covariates used for the model are highlighted in Table 5. Two-sided $p$-values were calculated for all tests, with $p<0.05$ considered as statistically significant. Statistical analysis was performed using SPSS v25 (IBM, USA). The Kaplan-Meier survival analysis was also done using time from admission as the starting point to either discharged alive or in-hospital death as the end-point.

\section{Results}

\section{Characteristics of Study Participants}

Four hundred sixty-nine African-American patients were admitted due to COVID-19 with a median age of 66 years (Table 1). The most common medical comorbidities observed were hypertension $(n=304,64.8 \%)$, diabetes $(n=200,42.6 \%)$, and dyslipidemia $(n=74,15.8 \%)$. Four hundred twenty-six (90.8\%) identified themselves as never smokers, $80.4 \%(n=377)$ had taken at least one dose of azithromycin, and 55.0\% $(n=258)$ were given hydroxychloroquine during the course of admission. Characterization of the cohort to non-obese (BMI $<30 \mathrm{BMI} \mathrm{kg} / \mathrm{m}^{2}, n=264$ ) vs. obese ( $\left.\geq 30 \mathrm{~kg} / \mathrm{m}^{2}, n=205\right)$ was done to measure statistical significance between the two groups. After univariate analysis, age, gender, asthma status, azithromycin, and hydroxychloroquine treatment were observed to have statistical significance $(p$-value $<0.001,<0.001,<0.001,0.013$, 0.017 , respectively).

\section{Clinical Presentation on Admission and Triage Vitals}

At triage, the most common presentations were shortness of breath $(n=306,65.2 \%)$, cough $(n=286,61.0 \%)$, fever/
Table 1 General characteristics of study participants

\begin{tabular}{lllll}
\hline Variable & All & $\begin{array}{l}\text { BMI }(<30) \\
n=264\end{array}$ & $\begin{array}{l}\text { BMI }(\geq 30) \\
n=205\end{array}$ & $p$-value \\
\hline Age (years) & $66.0(55.0-75.0)$ & $68.0(57.0-76.8)$ & $62.0(51.5-71.0)$ & $<0.001^{*}$ \\
BMI $\left(\mathrm{kg} / \mathrm{m}^{2}\right)$ & $28.8(52.4-28.8)$ & $25.8(13.9-27.8)$ & $35.1(32.4-39.5)$ & NA \\
Gender & & & & \\
$\quad$ Male & $264(64.8)$ & $171(64.8)$ & $93(45.4)$ & $<0.001^{*}$ \\
$\quad$ Female & $205(43.7)$ & $93(35.2)$ & $112(54.6)$ & \\
Smoking status & & & & \\
$\quad$ Smoker & $43(9.2)$ & $28(10.6)$ & $15(7.3)$ & 0.221 \\
$\quad$ Never smoker & $426(90.8)$ & $236(89.4)$ & $190(92.7)$ & 0.575 \\
Hypertension & $304(64.8)$ & $174(65.9)$ & $130(63.4)$ & 0.453 \\
Heart failure & $48(10.2)$ & $29(11.0)$ & $19(9.3)$ & 0.627 \\
Diabetes & $200(42.6)$ & $110(41.7)$ & $90(43.9)$ & $<0.001^{*}$ \\
Asthma & $61(13.0)$ & $22(8.3)$ & $39(19.0)$ & 0.973 \\
COPD & $46(9.8)$ & $26(9.8)$ & $20(9.8)$ & 0.950 \\
Coronary artery disease & $60(12.8)$ & $34(12.9)$ & $26(12.7)$ & 0.930 \\
Dyslipidemia & $74(15.8)$ & $42(15.9)$ & $32(15.6)$ & 0.64 \\
CKD & $50(10.7)$ & $22(8.3)$ & $28(13.7)$ & 0.674 \\
Psychiatric Disorders & $98(20.9)$ & $57(21.6)$ & $41(20.0)$ & 0.281 \\
Use of ACEI/ARBS & $42(9.0)$ & $27(10.2)$ & $15(7.4)$ & 0.881 \\
Length of stay (days) & $7.0(4.0-11.0)$ & $8.0(4.0-11.0)$ & $7.0(4.0-11.0)$ & \\
Treatment & & & $126(61.5)$ & $0.013^{*}$ \\
$\quad$ Hydroxychloroquine & $258(55.0)$ & $132(50.0)$ & $175(85.4)$ & $0.017^{*}$ \\
$\quad$ Azithromycin & $377(80.4)$ & $202(76.5)$ & & \\
\hline
\end{tabular}

Psychiatric disorder (schizophrenia, schizoaffective disorder, major depressive disorder, bipolar disorder, and anxiety disorder)

Age, BMI, and length of stay are presented as median (interquartile range). All other values represent frequency $(\%)$

Abbreviations: $B M I$, body mass index $\left(\mathrm{kg} / \mathrm{m}^{2}\right)$; $C O P D$, chronic obstructive pulmonary disease; $C K D$, chronic kidney disease; $A C E I$, angiotensin-converting enzyme inhibitors; $A R B$, angiotensin receptor blockers

$p$-values were obtained from $\chi^{2}$ test, or independent sample's $t$-test as appropriate

*Included in multivariate regression analysis to assess for predictors of morbidity 
chills $(n=241,51.4 \%)$, and myalgia $(n=191,40.7 \%)$ as shown in Table 2. After univariate analysis, temperature and pulse were shown to be significantly higher with the obese group ( $<0.001$ and 0.011 , respectively), and systolic blood pressure was found to be lower compared with the non-obese group. Temperature, respiratory rate, white blood cell count, and heart rate are the variables used to assess the systemic inflammatory syndrome-sepsis (SIRS-sepsis) score. SIRS criteria are mostly used as a screening tool to identify patients that may need a further workup for sepsis and severe sepsis. It is a triage tool that helps determine patient status and identify potentially septic patients and in need of further screening. Our results indicate temperature and pulse rates upon presentation were not only statistically significant but also clinically significant in guiding the clinical course of the patient.

Cough, fever/chills, and shortness of breath were also found to be statistically significant upon admission when comparing both BMI groups, and all had a higher percentage of occurring in the obese group (67.8 vs. $55.7 \%, p=0.008$; 58.0 vs. $46.2 \%, p=0.011 ; 72.2$ vs. $59.8 \%, p=0.005$, respectively).

\section{Laboratory Parameters}

Median values for inflammatory markers at admission are shown in Table 3. After univariate analysis, the study found that among patients diagnosed with COVID-19, serum procalcitonin $(p<0.001)$, sodium $(p=0.002)$, potassium $(p<0.001)$, and creatinine $(p<0.001)$ had statistically significant lower levels with the $\mathrm{BMI} \geq 30 \mathrm{~kg} / \mathrm{m}^{2}$ group when compared with the $<30 \mathrm{~kg} / \mathrm{m}^{2}$ BMI group. The opposite was true for serum bicarbonate $(p=0.007)$ and was found to be higher for the obese group (Table 3 ).

\section{In-Hospital Complications}

The total in-hospital mortality in the cohort was 152 (32.4\%). The obese group had more deaths compared to the non-obese group and was found to be statistically significant ( $n=85$ vs. $n=67$, respectively, $p<0.001$ ). The same was observed with mechanical ventilation, with more people being intubated with the obese group compared to the nonobese group ( $n=71$ vs. $n=60, p=0.004$ ) (Table 4).

\section{Predictors of Mortality in Obese Patients with COVID-19}

The multivariate regression analysis was used to analyze the obese cohort for clinical predictors of mortality (Table 5). Advanced age $(p=0.034)$, low sodium levels $(p=0.04)$, and elevated levels of AST (0.012) were associated with an increase in the likelihood of in-hospital death. Furthermore, the Kaplan Meier curve was used to determine survival time from admission to either death or discharged alive (Fig. 1). Median survival time was found to be significantly lower for the obese group (12 days) compared to the non-obese group, which was 24 days (log-rank test, $p=0.002$ ). The median survival time overall for the entire cohort was 22 days.

Table 2 Clinical presentation on admission and triage vitals

\begin{tabular}{|c|c|c|c|c|}
\hline Variable & All & $\begin{array}{l}\text { BMI }(<30) \\
n=264\end{array}$ & $\begin{array}{l}\text { BMI }(\geq 30) \\
n=205\end{array}$ & $p$-value \\
\hline Oxygen saturation (\%) & $96.0(92.0-98.0)$ & $96.0(93.0-98.0)$ & $95.0(92.0-97.0)$ & 0.117 \\
\hline Temperature $\left({ }^{\circ} \mathrm{F}\right)$ & $99.3(98.2-100.9)$ & $99.0(98.1-100.6)$ & $100.2(98.3-101.8)$ & $<0.001 *$ \\
\hline Respiratory rate (cycles/min) & $20.0(19.0-22.0)$ & $20.0(19.0-22.0)$ & $20.0(19.0-22.0)$ & 0.337 \\
\hline Pulse (beats/min) & $100.0(87.0-113.0)$ & $98.0(85.0-109.0)$ & $103.0(89.0-115.0)$ & $0.011 *$ \\
\hline Systolic blood pressure ( $\mathrm{mm} \mathrm{Hg}$ ) & $128.0(111.0-144.0)$ & $129.0(113.0-146.0)$ & $124.0(110.0-139.5)$ & $0.044 *$ \\
\hline Diastolic blood pressure ( $\mathrm{mm} \mathrm{Hg}$ ) & $75.0(65.5-83.0)$ & $76.0(66.0-83.75)$ & $74.0(65.0-82.0)$ & 0.103 \\
\hline \multicolumn{5}{|c|}{ Clinical presentation on admission and triage } \\
\hline Cough & $286(61.0)$ & $147(55.7)$ & $139(67.8)$ & $0.008 *$ \\
\hline Myalgia & $191(40.7)$ & $98(37.1)$ & $93(45.4)$ & 0.071 \\
\hline Fever/chills & $241(51.4)$ & $122(46.2)$ & $119(58.0)$ & $0.011 *$ \\
\hline Shortness of breath & $306(65.2)$ & $158(59.8)$ & $148(72.2)$ & $0.005 *$ \\
\hline Fatigue & $160(34.1)$ & $96(36.4)$ & $64(31.2)$ & 0.244 \\
\hline GI symptoms** & $119(25.4)$ & $64(24.2)$ & $55(26.8)$ & 0.523 \\
\hline
\end{tabular}

Clinical presentations were reported as frequency (\%). All other values are presented as median (interquartile range)

$P$-values were obtained from $\chi^{2}$ test, or independent samples $t$-test as appropriate

*Included in multivariate regression analysis

**GI symptoms include nausea, vomiting, diarrhea, and abdominal pain 
Table 3 Laboratory results of patients hospitalized with COVID-19

\begin{tabular}{|c|c|c|c|c|c|}
\hline Variable & All & BMI $(<30)$ & BMI $(\geq 30)$ & $p$-value & Normal range \\
\hline Hemoglobin (g/dL) & $12.8(11.1-14.0)$ & $12.6(11.0-14.1)$ & $12.8(11.3-13.9)$ & 0.764 & $12-14$ \\
\hline Platelets $\left(* 10^{6} / \mu \mathrm{L}\right)$ & $226.0(170.5-290.0)$ & $231.5(167.0-302.3)$ & $212.0(172.0-272.8)$ & 0.660 & $150-450$ \\
\hline $\operatorname{ESR}(\mathrm{mm} / \mathrm{Hr})$ & $73.0(47.5-100.0)$ & $78.0(52.0-102.0)$ & $70.0(44.3-97.8)$ & 0.535 & $0-22$ \\
\hline C-reactive protein $(\mathrm{mg} / \mathrm{L})$ & $104.0(53.5-184.0)$ & $106.0(47.0-199.0)$ & $104.0(56.5-176.0)$ & 0.484 & $0-10$ \\
\hline Troponin (ng/mL) & $0.03(0.03-0.10)$ & $0.03(0.03-0.07)$ & $0.03(0.03-0.16)$ & 0.109 & $0-0.03$ \\
\hline Brain natriuretic peptide $(\mathrm{pg} / \mathrm{mL})$ & $64.6(20.1-214.9)$ & $77.2(27.6-265.2)$ & $47.0(10.0-132.5)$ & 0.263 & $0-100$ \\
\hline Interleukin-6 (pg/mL) & $64.7(32.5-151.1)$ & $60.0(31.1-152.6)$ & $65.0(34.0-152.9)$ & 0.835 & $0-15.5$ \\
\hline Ferritin (ng/dl) & $810.0(452.0-1460.8)$ & $810.0(413.0-1351.0)$ & $830.0(470.0-1522.0)$ & 0.865 & $15-150$ \\
\hline Procalcitonin (ng/mL) & $0.90(0.2-2.3)$ & $1.1(0.3-4.3)$ & $0.7(0.2-2.2)$ & $<0.001^{*}$ & $0.00-0.08$ \\
\hline Serum sodium $(\mathrm{mmol} / \mathrm{L})$ & $138.0(134.0-141.0)$ & $138.0(134.0-141.0)$ & $134.0(135.0-141.0)$ & $0.002 *$ & $135-145$ \\
\hline Serum potassium $(\mathrm{mmol} / \mathrm{L})$ & $4.6(4.1-5.3)$ & $4.7(4.1-5.5)$ & $4.4(4.0-5.1)$ & $<0.001^{*}$ & $3.5-5.5$ \\
\hline Serum bicarbonate (meq/L) & $22.0(18.0-25.0)$ & $22.0(18.0-25.0)$ & $23.0(19.0-25.0)$ & $0.007 *$ & $22-26$ \\
\hline Blood urea nitrogen $(\mathrm{mg} / \mathrm{dL})$ & $22.2(13.3-42.1)$ & $24.0(14.2-44.2)$ & $21.0(12.3-40.3)$ & 0.618 & $10-20$ \\
\hline Serum creatinine $(\mathrm{mg} / \mathrm{dL})$ & $1.5(1.0-2.7)$ & $1.6(1.0-4.0)$ & $1.4(1.0-2.3)$ & $<0.001^{*}$ & $057-1.11$ \\
\hline Plasma glucose $(\mathrm{mg} / \mathrm{dL})$ & $127.0(100.0-215.8)$ & $127.0(96.0-204.0)$ & $127.0(103.0-231.5)$ & 0.060 & $80-115$ \\
\hline Magnesium (mg/dL) & $2.2(1.9-2.6)$ & $2.2(2.0-2.7)$ & $2.2(1.9-2.4)$ & 0.89 & $1.6-2.6$ \\
\hline APTT $(\mathrm{sec})$ & $31.3(28.7-34.3)$ & $31.2(28.8-34.7)$ & $31.7(28.6-34.3)$ & 0.727 & $25-36$ \\
\hline INR & $1.2(1.1-1.3)$ & $1.2(1.1-1.3)$ & $1.2(1.1-1.3)$ & 0.318 & $0.85-1.15$ \\
\hline Fibrinogen (mg/dL) & $498.0(432.8-692.0)$ & $516.5(466.0-696.5)$ & $490.0(424.0-666.0)$ & 0.301 & $193-507$ \\
\hline Lactic acid (mmol/L) & $1.7(1.3-2.3)$ & $1.8(1.3-2.5)$ & $1.6(1.3-2.3)$ & 0.630 & $0.5-1.9$ \\
\hline White blood cells $(* 1000 / \mu \mathrm{L})$ & $7.9(5.6-9.5)$ & $8.3(6.0-11.4)$ & $7.3(5.4-10.7)$ & 0.140 & $4.5-11$ \\
\hline Neutrophils $(* 1000 / \mu \mathrm{L}$ & $5.9(4.2-9.5)$ & $6.6(4.2-9.5)$ & $5.6(4.3-9.5)$ & 0.607 & $2.0-7.9$ \\
\hline Lymphocytes $(* 1000 / \mu \mathrm{L})$ & $0.9(0.6-1.3)$ & $0.9(0.6-1.3)$ & $0.9(0.6-1.3)$ & 0.714 & $10-4.8$ \\
\hline Aspartate aminotransferase (U/L) & $47.0(30.0-87.0)$ & $50.0(30.0-94.0)$ & $46.0(28.5-79.0)$ & $0.007 *$ & $5-34$ \\
\hline Alanine aminotransferase (U/L) & $31.0(17.0-50.0)$ & $29.0(16.0-49.0)$ & $31.0(19.5-52.0)$ & 0.265 & $10-55$ \\
\hline
\end{tabular}

$p$-values were obtained from Independent samples $t$-test

Abbreviations: APTT, activated partial thromboplastin time

*Included in multivariate regression analysis to assess for predictors of morbidity

Table 4 In-hospital complications

\begin{tabular}{llllc}
\hline Variable & Total $(n=469)$ & BMI $(<30)(n=264)$ & $\operatorname{BMI}(\geq 30)(n=205)$ & $p$-value \\
\hline In-hospital mortality & $152(32.4)$ & $67(25.4)$ & $85(41.5)$ & $<0.001^{*}$ \\
ICU care & $131(28.0)$ & $65(24.7)$ & $66(32.2)$ & 0.074 \\
Acute cardiac injury** & $285(60.8)$ & $102(38.6)$ & $82(40.0)$ & 0.764 \\
Septic shock & $63(13.4)$ & $30(11.4)$ & $33(16.1)$ & 0.136 \\
New onset renal replace- & $28(6.0)$ & $11(4.2)$ & $17(8.3)$ & 0.061 \\
$\quad$ ment therapy & & & $17(8.3)$ & 0.399 \\
Bacteremia & $45(9.6)$ & $28(10.6)$ & $71(34.6)$ & $0.004^{*}$ \\
Mechanical ventilation & $131(27.9)$ & $60(22.7)$ & &
\end{tabular}

*Included in multivariate regression analysis

**Acute cardiac injury is defined as an elevation of cardiac troponin I above 99th percentile upper reference limit or $(\geq 0.05 \mathrm{ng} / \mathrm{mL})$

\section{Discussion}

Obesity can be seen as a pandemic itself. According to the WHO, BMI is classified into six groups: underweight $\left(<18.5 \mathrm{~kg} / \mathrm{m}^{2}\right)$, normal $\left(18.5-24.9 \mathrm{~kg} / \mathrm{m}^{2}\right)$, pre-obesity $\left(25-29.9 \mathrm{~kg} / \mathrm{m}^{2}\right)$, obesity class I $\left(30-34.9 \mathrm{~kg} / \mathrm{m}^{2}\right)$, obesity class II $\left(35-39.9 \mathrm{~kg} / \mathrm{m}^{2}\right)$, and obesity class III $\left(>40 \mathrm{~kg} / \mathrm{m}^{2}\right)$. The worldwide prevalence of overweight $\left(\mathrm{BMI} \geq 25 \mathrm{~kg} / \mathrm{m}^{2}\right)$ and obesity have increased significantly 
Table 5 Output from multivariate logistic regression assessing for predictors of mortality in obese patients with admitted for COVID-19

\begin{tabular}{lll}
\hline Variable & OR $(95 \%$ CI $)$ & $p$-value \\
\hline Age & $1.199(1.014-1.418)$ & 0.034 \\
Gender & $0.068(0.004-1.258)$ & 0.071 \\
Smoking history & $0.169(0.001-26.177)$ & 0.490 \\
Hypertension & $0.203(0.009-4.577)$ & 0.316 \\
Heart failure & $0.317(0.001-74.433)$ & 0.680 \\
Diabetes & $0.326(0.018-5.824)$ & 0.446 \\
COPD & $50.949\left(0.003-9.11 \times 10^{5}\right)$ & 0.431 \\
CAD & $8.107(0.187-351.077)$ & 0.431 \\
Dyslipidemia & $0.082(0.003-2.215)$ & 0.137 \\
CKD & $0.001(0.000-11.304)$ & 0.147 \\
ICU stay & $3.95 \times 10^{8}\left(0.508-3.07 \times 10^{17}\right)$ & 0.058 \\
Septic shock & $24.698(0.209-2914.119)$ & 0.188 \\
Troponin & $12.160(0.530-279.067)$ & 0.118 \\
Procalcitonin & $1.439(0.699-2.963)$ & 0.323 \\
Serum sodium & $1.563(1.1-2.454)$ & 0.04 \\
HCO3 & $0.770(0.546-1.087)$ & 0.137 \\
BUN & $1.045(0.970-1.125)$ & 0.247 \\
Creatinine & $0.796(0.449-1.409)$ & 0.433 \\
Magnesium & $0.921(0.667-1.271)$ & 0.616 \\
AST & $1.053(1.011-1.097)$ & 0.012 \\
Ferritin & $1.000(0.999-1.002)$ & 0.491 \\
IL-6 & $1.005(0.997-1.014)$ & 0.241 \\
\hline
\end{tabular}

Abbreviations: $B M I$, body mass index; $A S T$, aspartate aminotransferase; $I L-6$, interleukin-6; $B U N$, blood urea nitrogen; $C A D$, coronary artery disease; $C K D$, chronic kidney disease; $I C U$, intensive care unit; $C O P D$, chronic obstructive pulmonary disease and extent that nearly a third of the world population. The trend in obesity has increased in adults and children of all ages. The United States of America and Europe are two regions with the highest prevalence of obesity. According to the $\mathrm{CDC}$, the age-adjusted prevalence of obesity is $42.4 \%$ and $9.4 \%$ for severe obesity [12-14].

Obesity may contribute to increased morbidity in patients with COVID-19 infection. It is known that obesity results in the dysregulated immune response to respiratory infections and greatly impacts normal lung function. This can be explained as fat deposits in obesity alter the mechanics of the chest wall and lungs, thus reducing lung compliance. The work of breathing is increased to meet the oxygen demand of the body in ARDS, and there have been reports of increased production of inflammatory cells and airway hyper-responsiveness by excess adiposity $[15,16]$.

In the study by Leonidas et al. in Bronx, NY, fever (86\%) and cough $(76.5 \%)$ were the two most common symptoms at presentation, whereas we found shortness of breath $(n=306$, $65.2 \%)$ and cough $(n=286,61.0 \%)$. In total, $24 \%$ of their cohort died during hospitalization (compared to $32 \%$ in our study), with higher rates among individuals with severe obesity (BMI $<25 \mathrm{~kg} / \mathrm{m}^{2} 31.6 \%$, BMI $25-34 \mathrm{~kg} / \mathrm{m}^{2} 17.2 \%$, BMI $\left.\geq 35 \mathrm{~kg} / \mathrm{m}^{2} 34.8 \%, p=0.030\right)$. Similarly, patients with severe obesity were more likely to undergo intubation (BMI $<25 \mathrm{~kg} / \mathrm{m}^{2} 18.4 \%$, BMI $25-34 \mathrm{~kg} / \mathrm{m}^{2} 16.4 \%$, $\mathrm{BMI} \geq 35 \mathrm{~kg} / \mathrm{m}^{2} 34.8 \%, p=0.032$ ) [11].

In the meta-analysis by A.Y. Soroeto et al., comparing ten studies showed that obesity was associated with poor outcomes. Subgroup analysis showed that obesity was associated with other poor outcomes (ARDS, severe COVID-19,
Fig. 1 Kaplan-Meier survival curve of patients admitted for COVID-19 comparing the two BMI groups at Interfaith Medical Hospital. Note: BMI values are expressed as $\mathrm{kg} / \mathrm{m}^{2}$. $P$-value using log-rank (Mantel-Cox) test is significant at $p=0.002$

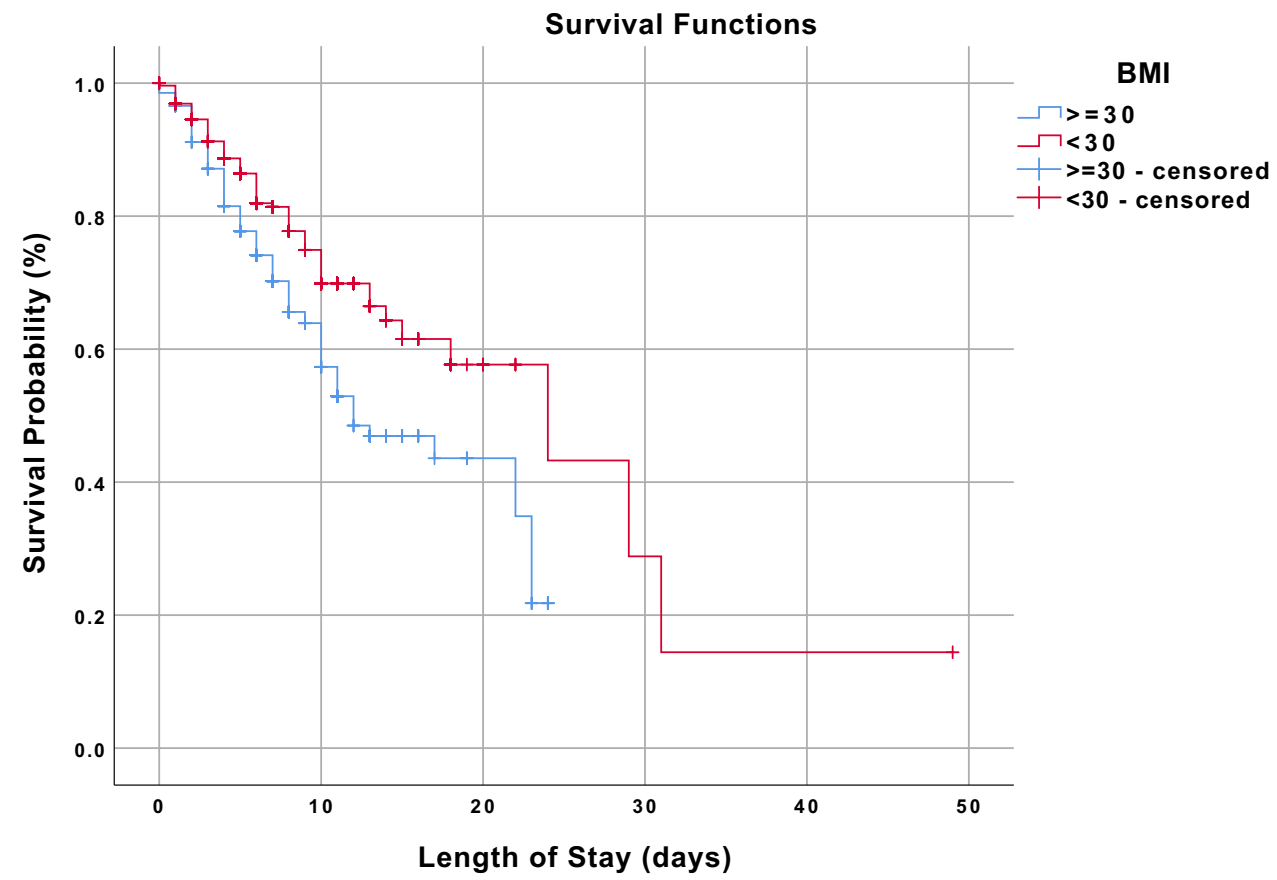


use of mechanical ventilation, and hospital admission) with but not associated with ICU admission [17]. Peng et al. published a retrospective analysis on 112 patients with COVID-19 infection admitted to the western district of Union Hospital in Wuhan from 20 January to 15 February 2020. In this study, the BMI of the critical group (25.5 [23.0, $27.5] \mathrm{kg} / \mathrm{m}^{2}$ ) was significantly higher than that of the general group $\left(22.0[20.0,24.0] \mathrm{kg} / \mathrm{m}^{2}\right)$. Patients were further divided into two groups, survivors (84.8\%) and non-survivors $(15.18 \%)$. Among the non-survivors, $88.2 \%$ of patients had a BMI $>25 \mathrm{~kg} / \mathrm{m}^{2}$, which is a significantly higher proportion than in survivors (18.9\%) [18]. In our analysis, the total in-hospital mortality in the cohort was $32.4 \%$. The deaths in the obese group were found to be statistically significant. The same was observed with mechanical ventilation, with more people being intubated with the obese group compared to the non-obese group.

In our study, more patients were intubated within the obese group compared to the non-obese group. Similar findings were seen in a French study; the risk for invasive mechanical ventilation in patients with COVID-19 infection admitted to the intensive treatment unit was more than sevenfold higher for those with body mass index (BMI) $>35$ compared with BMI $<25 \mathrm{~kg} / \mathrm{m}^{2}$. Among individuals with COVID-19 who were $<60$ years of age in New York City, those with a BMI between 30 to 34 and $>35 \mathrm{~kg} / \mathrm{m}^{2}$ were 1.8 times and 3.6 times more likely to be admitted to critical care, respectively, than individuals with a BMI $<30 \mathrm{~kg} / \mathrm{m}^{2}$ $[19,20]$.

In a pooled analysis by Lippi et al., serum sodium, potassium, chloride, and calcium were compared between COVID-19 patients with and without the severe disease. The COVID-19 severity was associated with lower serum concentrations of sodium, potassium, and calcium [21]. Our study showed low sodium levels as a predictor of mortality in obese patients. We recommend electrolytes be measured at initial presentation and serially monitored during hospitalization in order to establish timely and appropriate corrective actions. Further large-scale studies are needed further to analyze the electrolyte imbalance in COVID-19 obese patients.

The age-adjusted death rate per 100,000 people in NYC is more than double for African-Americans than Whites (127.1 vs. 63.5). The higher prevalence of medical conditions that are considered risk factors for severe COVID-19 among African-Americans and a higher risk for exposure to SARS-CoV-2 due to living and working conditions seem to be plausible explanations for the observed disproportionate differences in outcomes [22, 23].

Limitations of the study include the sample size. A similar study model can be expanded to other medical centers in the area. Generalization of the findings to the population will need more number of cases. The data is obtained from patient charts, which is pre-recorded, and may have shortcomings of validity and accuracy. However, a thorough chart review by an independent reviewer ensured to minimize the errors.

\section{Conclusions}

Obesity and its complications, particularly diabetes and hypertension, increase the morbidity and mortality in patients with SARS COVID-19 infection. There is a significant prevalence of obesity in the Afro-American population in New York. Higher morbidity and mortality are seen in the Afro-American population as compared to other races. Obesity is associated with higher rates of complications, higher oxygen requirement, higher chances of intubation, and increased mortality in the Afro-American population with SARS-CoV-2 infection. This cohort of population is at significant risk for complications once infected with COVID-19; hence, it needs special attention.

Author Contribution Dr. Gayam, Dr. Garlapati, and Dr. Kumar proposed the concept, designed the study, wrote the protocol, and managed the study. Dr. Kumar and Dr. Garlapati interpreted the data, and wrote the manuscript. Dr. Meet Patel and Dr. Bidyut Sarker were involved in collecting the data. Dr. Benjamin performed the statistics. Dr Adapa, Dr. Sohail, and Dr. Adler performed a critical review of the manuscript. All authors provided inputs for revision of the manuscript. Dr. Gayam communicated with the journal and addressed comments from reviewers. All the authors vouch for the integrity and completeness of the data presented and agreed to submit the manuscript for publication.

\section{Declarations}

Conflict of Interest The authors declare no competing interests.

\section{References}

1. Cucinotta D, Vanelli M. WHO declares COVID-19 a pandemic. Acta Biomed. 2020;91(1):157-60. https://doi.org/10.23750/abm. v91i1.9397.

2. Chen T, Wu D, Chen H, Yan W, Yang W, Chen G, et al. Clinical characteristics of 113 deceased patients with coronavirus disease 2019: Retrospective study. BMJ. 2020;368: m1091. https://doi. org/10.1136/bmj.m1091.

3. Zhou F, Yu T, Du R, Fan G, Liu Y, Liu Z, et al. Clinical course and risk factors for mortality of adult inpatients with COVID19 in Wuhan, China: a retrospective cohort study. Lancet. 2020;395(10229):1054-62. https://doi.org/10.1016/S01406736(20)30566-3.

4. Yang J, Zheng Y, Gou X, Pu K, Chen Z, Guo Q, et al. Prevalence of comorbidities and its effects in coronavirus disease 2019 patients: a systematic review and meta-analysis. Int J Infect Dis. 2020;94:91-5. https://doi.org/10.1016/j.ijid.2020.03.017.

5. Zheng Z, Peng F, Xu B, Zhao J, Liu H, Peng J, et al. Risk factors of critical \& mortal COVID-19 cases: a systematic literature 
review and meta-analysis. J Infect. 2020;S0163-4453(20):302346. https://doi.org/10.1016/j.jinf.2020.04.021.

6. Kim NY, Ha E, Moon JS, Lee Y-HH, Choi EY. Acute hyperglycemic crises with coronavirus disease-19: case reports. Diabetes Metab J. 2020;44(2):349-53. https://doi.org/10.4093/dmj.2020. 0091.

7. Guan W, Liang W, Zhao Y, Liang H-R, Chen Z-Sh, Yi-Min $\mathrm{Li}$, et al. Comorbidity and its impact on 1590 patients with COVID-19 in China: a nationwide analysis. Eur Respir J. 2020;55(5):2000547. https://doi.org/10.1183/13993003. 00547-2020.

8. Cure E, Cumhur CM. Angiotensin-converting enzyme inhibitors and angiotensin receptor blockers may be harmful in patients with diabetes during COVID-19 pandemic. Diabetes Metab Syndr Clin Res Rev. 2020;14(4):349-50. https://doi.org/10.1016/j.dsx.2020. 04.019 .

9. Cheng Y, Luo R, Wang K, Zhang M, Wang Z, Dong L, et al. Kidney disease is associated with in-hospital death of patients with COVID-19. Kidney Int. 2020;97(5):829-38. https://doi.org/ 10.1016/j.kint.2020.03.005.

10. Williamson EJ, Walker AJ, Bhaskaran K, Bacon S, Bates C, Morton CE, Curtis HJ, Mehrkar A, Evans D, Inglesby P, Cockburn J, McDonald HI, MacKenna B, Tomlinson L, Douglas IJ, Rentsch CT, Mathur R, Wong AYS, Grieve R, Harrison D, Forbes H, Schultze A, Croker R, Parry J, Hester F, Harper S, Perera R, Evans SJW, Smeeth L, Goldacre B. Factors associated with COVID-19-related death using OpenSAFELY. Nature. 2020;584(7821):430-436. https://doi.org/10.1038/ s41586-020-2521-4.

11. Palaiodimos L, Kokkinidis DG, Li W, et al. Severe obesity, increasing age and male sex are independently associated with worse in-hospital outcomes, and higher in-hospital mortality, in a cohort of patients with COVID-19 in the Bronx. New York Metabolism. 2020;108: 154262. https://doi.org/10.1016/j.metab ol.2020.154262.

12. CDC Available from: https://www.cdc.gov/obesity/adult/defining. html. Accessed 10/4/20

13. Chooi YC, Ding C, Magkos F. The epidemiology of obesity. Metab Clin Exp. 2019;92:6-10.

14. Michalakis K, Goulis DG, Vazaiou A, Mintziori G, Polymeris A, Abrahamian-Michalakis A. Obesity in the ageing man. Metab Clin Exp. 2013;62(10):1341-9.
15. Dixon AE, Peters U. The effect of obesity on lung function Expet Rev. Respir Med. 2018;12(9):755-67.

16. Kulcsar KA, Coleman CM, Beck SE, Frieman MB. Comorbid diabetes results in immune dysregulation and enhanced disease severity following MERS-CoV infection. JCI Insight. 2019;4(20):e131774. https://doi.org/10.1172/jci.insight.131774.

17. Soeroto AY, Soetedjo NN, Purwiga A, Santoso P, Kulsum ID, Suryadinata H, Ferdian F. Effect of increased BMI and obesity on the outcome of COVID-19 adult patients: A systematic review and meta-analysis. Diabetes Metab Syndr. 2020;14(6):18971904. https://doi.org/10.1016/j.dsx.2020.09.029.

18. Peng YD, Meng K, Guan HQ, et al. Clinical characteristics and outcomes of 112 cardiovascular disease patients infected by 2019nCoV. Zhonghua Xin Xue Guan Bing Za Zhi. 2020;48:E004.

19. Simonnet A, Chetboun M, Poissy J, Raverdy V, Noulette J, Duhamel A, Labreuche J, Mathieu D, Pattou F, Jourdain M, Lille Intensive Care CO- VID-19 and Obesity Study Group. High prevalence of obesity in severe acute respiratory syndrome coronavirus-2 (SARS-CoV-2) requiring invasive mechanical ventilation [published online April 9, 2020]. Obesity (Silver Spring). https:// doi.org/10.1002/oby.22831. https://onlinelibrary.wiley.com/doi/ 10.1002/oby.22831.

20. Lighter J, Phillips M, Hochman S, Sterling S, Johnson D, Francois $\mathrm{F}$, Stachel A. Obesity in patients younger than 60 years is a risk factor for COVID-19 hospital admission [published online April 9, 2020]. Clin Infect Dis. 2020. https://doi.org/10.1093/cid/ciaa4 15. https://academic.oup.com/cid/advance-article/doi/10.1093/ $\mathrm{cid} / \mathrm{ciaa} 415 / 5818333$.

21. Lippi G, Plebani M. Laboratory abnormalities in patients with COVID-2019 infection. Clin Chem Lab Med. 2020;58(7):1131-4. https://doi.org/10.1515/cclm-2020-0198.

22. New York City Department of Health Coronavirus disease 2019 (COVID-19). COVID-19: data. https://www1.nyc.gov/site/doh/ covid/covid-19-data.page. Accessed 10/4/20

23. Yancy CW. COVID-19 and African Americans. Jama. https://doi. org/10.1001/jama.2020.6548.

Publisher's Note Springer Nature remains neutral with regard to jurisdictional claims in published maps and institutional affiliations. 